\title{
Utilização da metodologia "Grounded Theory" na identificação de informações para compor um plano de dados abertos de instituições federais de ensino superior
}

\author{
Daniel Fernando Carossi' ${ }^{1}$, José Gilson A. Teixeira Filho², Juliane M. Pedãn ${ }^{3}$ \\ ${ }^{1}$ Instituto Federal de Educação, Ciência e Tecnologia de Santa Catarina (IFSC), Bairro \\ São Luiz, Rua 22 de abril, nº 2440, São Miguel do Oeste - SC - Brasil \\ ${ }^{2}$ Universidade Federal de Pernambuco, Av. Prof. Moraes Rego, 1235, Cidade \\ Universitária, Recife - PE - Brasil \\ ${ }^{3}$ Centro Universitário UNINTER - São Miguel do Oeste, SC - Brasil \\ daniel.carossi@ifsc.edu.br, gilson.teixeira@ufpe.br, \\ julianemariapedan@gmail.com
}

\begin{abstract}
Open Data refers to a concept created to make information freely available on the Internet, and, in the governmental sphere, seeks to foster transparency and innovation in public management. In view of the importance of the topic, the recent normative instruments published in Brazil governing the subject and the need to make relevant data available, the present article aimed to carry out an investigation in search of the topics most demanded by the company registered in the Electronic Information Service System Citizen. Using the Grounded Theory methodology for survey and analysis of the requests, the research used data associated with 104 Federal Institutions of Higher Education, of which 20 categories with 144 associated topics were identified that indicate a set of priority data demanded by the society.
\end{abstract}

Resumo: "Dados Abertos" referem-se a um conceito criado para disponibilizar informações de forma livre na internet, e, no âmbito governamental, busca fomentar a transparência e a inovação na gestão pública. Tendo em vista a importância do tema, dos recentes instrumentos normativos publicados no Brasil regendo o assunto e a necessidade de disponibilizar dados relevantes, o presente artigo teve como objetivo realizar uma investigação em busca dos temas mais demandados pela sociedade registrados no Sistema Eletrônico do Serviço de Informações ao Cidadão. Utilizando-se da metodologia Grounded Theory para levantamento e análise das solicitações, a pesquisa utilizou dados associados a 104 Instituições Federais de Ensino Superior, dos quais foram identificadas 20 categorias com 144 Temas Associados que indicam um conjunto de dados prioritários demandados pela sociedade. 


\section{Introdução}

Contribuir para o aumento da transparência e disponibilização de informações sobre as atividades do governo é um dos principais objetivos assumidos pelo Brasil diante do acordo firmado em 2011, denominado de Parceria para o Governo Aberto - OGP (do inglês, Open Government Partnership), cuja finalidade é fomentar a participação da sociedade no desenvolvimento do Estado, possibilitando a fiscalização do governo, o empoderamento do cidadão e a participação da sociedade no desenvolvimento de soluções inovadoras para a administração pública [OGP, 2011]. Essa parceria determinou que os países participantes assumissem compromissos denominados de planos de ação, para atender aos princípios da proposta de governo aberto (transparência, accountability ${ }^{1}$, participação cidadã e tecnologia e inovação).

No mesmo ano em que o Brasil assumiu o compromisso junto a OGP, foi sancionada a Lei $n^{\circ}$ 12.527, Lei de Acesso à Informação [BRASIL, 2011], que obriga as instituições públicas Federais, Estatuais e Municipais a disponibilizarem informações, independentemente de solicitações, em meios digitais em portais na internet, salvo aquelas resguardadas por sigilo.

Com a publicação da lei, o Brasil tornou-se, no ano de 2011 , “... o $13^{\circ}$ país na América Latina e o $91^{\circ}$ país do mundo a conferir aos cidadãos os mecanismos concretos que asseguram o direito de acesso a informações públicas." [MICHENER, MONCAU e VELASCO, 2014, p. 10]. A lei é um marco para a transparência brasileira, pois estabelece a obrigação das instituições divulgarem informações de forma ativa, ou seja, independente de solicitações da sociedade. Qualquer informação produzida ou custodiada pela administração pública deve ser disponibilizada de forma pública, informações como dados processados ou não, contidos em qualquer meio ou formato devem ser publicizados [BRASIL, 2011].

\section{Dados Abertos e Transparência}

Dados abertos e transparência pública se complementam principalmente no objetivo de disponibilizar informações e promover mais visibilidade das ações públicas à sociedade.

Dados abertos são aqueles que podem ser livremente utilizados, reutilizados e redistribuídos por qualquer pessoa, cuja exigência básica seria de atribuição à fonte original e compartilhamento pelas mesmas licenças em que as informações foram apresentadas [OPEN DEFINITION, 2015]. Isotani e Bittencourt (2015) complementam que, tanto pessoas físicas quanto jurídicas podem usar e redistribuir tais informações.

Por este prisma, Eaves (2009), complementa que: se o dado não pode ser encontrado e indexado na rede de computadores, ele não existe; se não estiver aberto e disponível em formato compreensível por máquina, ele não pode ser reaproveitado; se não for livre de utilização, ou seja, tiver restrição para seu uso, não pode ser considerado dado aberto.

Diniz (2010, p.8) aponta que: “A disponibilização de dados governamentais abertos só tem valor se houver interesse da sociedade civil em reutilizá-los, dando a eles novos significados segundo o seu interesse e conveniência". Nessa perspectiva, o Centro Regional para o Desenvolvimento da Sociedade da Informação destaca a

\footnotetext{
${ }^{1}$ Accountability: prestação de contas, ética.
} 
importância da geração de dados relevantes para a sociedade, para que essas informações contribuam para a formulação e implementação de políticas públicas, e que as informações produzidas e disponibilizadas pelas instituições tragam maior valor à sociedade [CETIC.br, 2013].

Neste sentido, Pedroso et al. (2013) menciona que, “[...] determinar o que deve ser divulgado sobre um determinado assunto não é algo simples, já que requer a definição de critérios e, por vezes, o conhecimento do domínio da informação". Pesquisas e trabalhos nesta área "[...] podem e muito contribuir com soluções para identificação de grupos de informações relevantes para cada contexto [...]". Tal afirmação é compartilhada por Chignard (2013) quando frisa que a diversidade de objetivos é um grande problema para as instituições, principalmente quando se trata de escolher quais dados serão divulgados à sociedade em formato aberto.

Tendo em vista a importância do tema e as iniciativas desenvolvidas para ampliar a transparência de informações, o estudo mostra-se relevante por tratar de questões de interesse da sociedade e que apresentam impacto significativo para o cidadão brasileiro. Utilizando-se da Grounded Theory, foi possível identificar as demandas geradas pela sociedade, armazenadas no Sistema Eletrônico do Serviço de Informações ao Cidadão (e-SIC), sistema que gerencia e administra todos os pedidos de informação demandados aos órgãos públicos do Poder Executivo Federal.

\section{Metodologia}

Por meio de pesquisa de campo foram coletados documentos referentes aos pedidos de acesso à informação registrados no Sistema Eletrônico do Serviço de Informações ao Cidadão - e-SIC das Instituições Federais de Ensino Superior - IFES. Farias e Arruda (2000, p.67) identificam uma pesquisa de campo, “... quando a coleta de dados e informações ou as observações são realizadas no ambiente em que o objeto está situado no local de manifestação do fenômeno pesquisado, in natura".

A pesquisa de campo objetivou coletar informações registradas pelo e-SIC e armazenadas nas bases de dados das instituições, mencionadas na literatura como documentos secundários, "(pesquisa documental)", isto é, onde "a fonte de dados e de informações são os documentos; é por intermédio deles que se responderão às questões de pesquisa..." [FARIAS E ARRUDA, 2000, p.65]. Gil (2008, p. 50) complementa que "... a pesquisa documental vale-se de materiais que não receberam ainda um tratamento analítico, ou que ainda podem ser reelaborados de acordo com os objetivos da pesquisa".

Para análise das informações utilizou-se a metodologia Grounded Theory (Teoria Fundamentada em Dados). Strauss e Corbin (2008, p. 25) destacam que "A teoria fundamentada em dados tende a se parecer mais com a 'realidade' do que a teoria derivada da reunião de uma série de conceitos baseados em experiência...”. A teoria apresenta um maior discernimento sobre o contex to abordado baseada na interpretação dos dados e não na opinião de quem vivencia determinada realidade. Dessa forma, optou-se pela utilização da Grounded Theory pelo fato de o aprendizado surgir a partir da análise dos dados e não a partir de uma visão ou opinião teórica pré-existente.

Strauss e Corbin (2008) ao apresentar a Grounded Theory definem suas fases como: codificação aberta, codificação axial e codificação seletiva, as quais são ilustradas na Figura 1. 
Figura 1 - Ilustração do Processo de Coleta e Análise da Grounded Theory

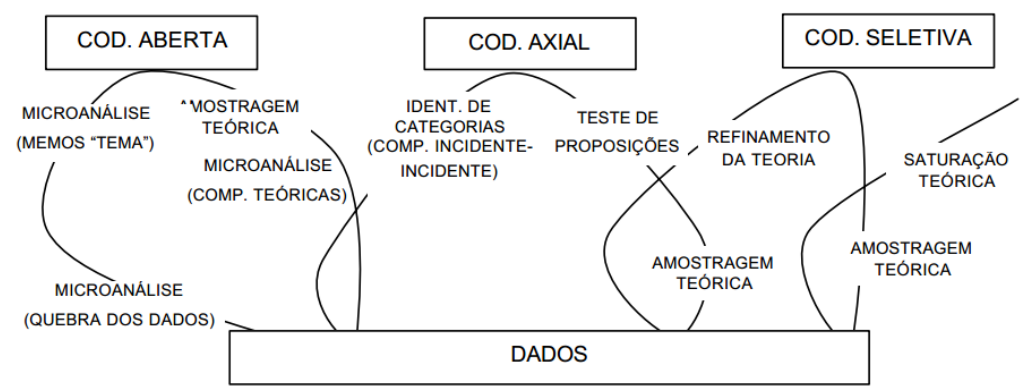

Fonte: Bandeira de Mello (2003)

A codificação aberta contempla a etapa de análise e interpretação dos dados, na qual o pesquisador realiza a conceituação e categorização dos dados. A conceituação tem por finalidade identificar propriedades do texto e associá-las a códigos na medida em que vão surgindo no contexto analisado. Strauss e Corbin (2008, p.104) definem codificação aberta como um processo de abrir o texto e expor seus significados relacionando-os em conceitos mais abstratos, chamados de "categorias". Durante esta fase, também é registrado observações, denominadas de "memorandos" cujo objetivo é anotar as principais ideias encontradas no corpo do texto avaliado.

De acordo com Creswell (2010), ao se analisar dados qualitativamente, o pesquisador deve seguir alguns passos fundamentais para o sucesso do processo. Tendo acesso aos dados coletados, os mesmos devem ser organizados e preparados para a aplicação das análises visando identificar ideias centrais apresentadas no contexto. $\mathrm{O}$ autor destaca que:

Isso envolve manter os dados de texto, ou as figuras, reunidos durante a coleta de dados, segmentando sentenças (ou parágrafos) ou imagens em categorias e rotulando essas categorias com um termo, com frequência um termo baseado na linguagem real do participante (chamado um termo in vivo) Creswell (2010, p.218-219).

Na fase de codificação axial, segunda fase da Grounded Theory, o pesquisador realiza a associação/relacionamento entre as categorias e subcategorias (subtemas) encontradas no texto analisado, levando em consideração as propriedades e dimensões identificadas na codificação aberta. Strauss e Corbin (2008, p.124) explicam que "o objetivo da codificação axial é começar o processo de reagrupamento dos dados que foram divididos durante a codificação aberta". A associação ou relacionamento pode ser definido por: condições causais, intervenientes, consequências e estratégias de ações ou interações, segundo Strauss e Corbin (2008).

Farias e Arruda (2000) ao discorrer sobre estratégias de avaliação qualitativa abordam o método Grounded Theory e destacam que uma boa estratégia para o tratamento das informações é realizar a seleção dos dados brutos e transformá-los em dados capazes de dar coerência ao contexto avaliado. Esses resultados podem ser apresentados em formato de gráficos, esquemas ou tabelas e concluem que a identificação de padrões contribui para a conclusão da pesquisa.

Para auxiliar na etapa de categorização (codificação axial) foi utilizada uma lista de conectores para construir esquemas de identificação dos principais assuntos demandados às IFES. 
No Quadro 1, é ilustrada uma proposta apresentada por Strauss e Corbin (1998) para a associação e identificação das categorias, utilizada durante a realização desta pesquisa.

\section{Quadro 1. Descrição dos conectores}

\begin{tabular}{|r|l|}
\hline Rótulo & Descrição \\
\hline is a a & $\begin{array}{l}\text { O código-origem é um tipo, ou forma, do código-destino. É } \\
\text { definido por um padrão de variação dimensional ao longo das } \\
\text { propriedades da categoria (código-destino). }\end{array}$ \\
\hline is associated with & $\begin{array}{l}\text { O código-origem e o código-destino têm conceitos específicos } \\
\text { relacionados. }\end{array}$ \\
\hline is cause of & $\begin{array}{l}\text { O código-origem (condição causal) causa a ocorrência do código- } \\
\text { destino. }\end{array}$ \\
\hline is part of & $\begin{array}{l}\text { O código-origem é uma parte que compõe juntamente com outras } \\
\text { partes o código-destino. }\end{array}$ \\
\hline is property of & O código-origem é propriedade de outro código-destino. \\
\hline
\end{tabular}

Fonte: adaptado de Conte et al. (2009)

Por fim, a codificação seletiva, terceira fase do método Grounded Theory, é o processo de integração e refinamento das informações surgidas dos dados. Nesta etapa o pesquisador reavalia as categorias e busca identificar se alcançou ou não a saturação teórica do tema.

O critério final para determinar se devemos ou não finalizar os processos de coleta de dados ainda é a saturação teórica. Esse termo denota que, durante a análise, não surgem nos dados novas propriedades e dimensões, e que a análise responde por grande parte da possível variabilidade (STRAUSS E CORBIN, 2008, p. 157).

Dessa forma, o pesquisador deve atentar para as informações relevantes para o contexto do tema e deixar de lado teorias que não se ajustam ao tema. Pois, “... não há razão para associar uma teoria com conceitos que não levam a lugar nenhum ou que pouco contribuem para seu entendimento" [STRAUSS E CORBIN, 2008, p.157].

\subsection{Universo da pesquisa}

A pesquisa envolveu Instituições Federais de Ensino Superior, sendo, Universidades Federais, Institutos Federais de Educação Ciência e Tecnologia, Centros Federais de Educação Tecnológica e o Colégio Pedro II.

O número de instituições utilizadas na pesquisa foi baseado nos resultados coletados em consulta realizada no sítio do MEC (http://emec.mec.gov.br), na data de 15 de abril de 2016. O sítio do MEC contém a base de dados oficial de informações relativas às Instituições de Educação Superior do Sistema Federal de Ensino.

Os dados coletados foram solicitados via pedido de acesso a informação encaminhado pelo e-SIC a todas as IFES. O pedido foi registrado na data de 8 de julho de 2016. Do total de instituições envolvidas na pesquisa, 73 concederam acesso a informação, destas, apenas 60 atenderam ao pedido de acordo com o solicitado, as demais (13 instituições) encaminharam como retorno um arquivo em formato proprietário (.pdf), e com colunas faltando, o que impossibilitou a análise das informações. Cabe destacar que 16 IFES não atenderam o prazo estabelecido na Lei da Acesso à Informação - LAI para retorno de informação e 15 instituições negaram o 
acesso, e alegaram os seguintes motivos: complexidade para obter a informação; necessidade de tratamento adicional de dados para disponibilização da informação; e número limitado de servidores para atender a solicitação.

De posse das informações coletadas, foram selecionadas para aplicação da Grounded Theory, aleatoriamente, solicitações das 60 instituições que atenderam ao pedido de informação, ao todo, as 60 instituições tiveram um total de 21.336 pedidos registrados no período avaliado.

\subsection{Aplicação da Grounded Theory}

O Quadro 2 apresenta um trecho de conteúdo analisado pela metodologia. No Quadro são listadas seis solicitações, das quais alguns trechos foram destacados (fase de codificação aberta) pelo pesquisador para compor as categorias e temas prioritários demandados pela sociedade.

Quadro 2. Parte dos conteúdos solicitados, direcionados as IFES

\begin{tabular}{|l|}
\hline Descrição da Solicitação \\
\hline $\begin{array}{l}\text { Solicito informações referentes ao quantitativo dos servidores ativos (docentes e técnico } \\
\text { administrativos) deste Instituto Federal, discriminados em função do grau de escolaridade } \\
\text { do servidor, conforme tabela em arquivo anexo. Solicito que as informações sejam relativas } \\
\text { aos dados mais recentes disponíveis pelo setor de Recursos Humanos. Obrigado. }\end{array}$ \\
\hline $\begin{array}{l}\text { Prezados, Solicito a informação quanto à existência de códigos de vagas para o cargo de } \\
\text { Assistente Social (Nível E) e a informação se há concurso vigente para o referido cargo } \\
\text { nesta instituição. Att, }\end{array}$ \\
\hline $\begin{array}{l}\text { Gostaria de obter informações sobre os cursos oferecidos por esta Instituição e a } \\
\text { quantidade de alunos em cada curso, todos os turnos, no período de } 2010,2011,2012 \text { e } \\
2013 .\end{array}$ \\
\hline $\begin{array}{l}\text { Solicito a relação das despesas da UFAL fixadas para o exercício } 2013 \text { com os respectivos } \\
\text { valores e classificadas por fonte de recursos. }\end{array}$ \\
\hline $\begin{array}{l}\text { Quanto o valor total da verba repassada pelo governo federal para esta universidade no } \\
\text { período letivo do ano } 2012 ?\end{array}$ \\
\hline Preciso resolver as atividades complementares. \\
\hline
\end{tabular}

Para identificação dos resultados foram analisadas 5.250 solicitações, as quais permitiram encontrar a saturação teórica do tema como proposto pela metodologia. Das solicitações que passaram pelas fases da Grounded Theory, apenas 3.960 foram consideradas, 1.290 solicitações não tinham clareza em seu conteúdo, impossibilitando, assim, a identificação do tema. Como exemplo, destaca-se a última solicitação contida no Quadro, na qual o demandante não deixa claro o objetivo de sua solicitação.

Na Figura 2 está um exemplo do processo aplicado para identificação do conjunto de categorias e temas propostos pelo trabalho. A figura apresenta o conteúdo das solicitações, os códigos criados e as observações registradas com auxílio da ferramenta Atlas.ti. 
Figura 2. Codificação Aberta com suporte do software Atlas.ti Criação dos códigos

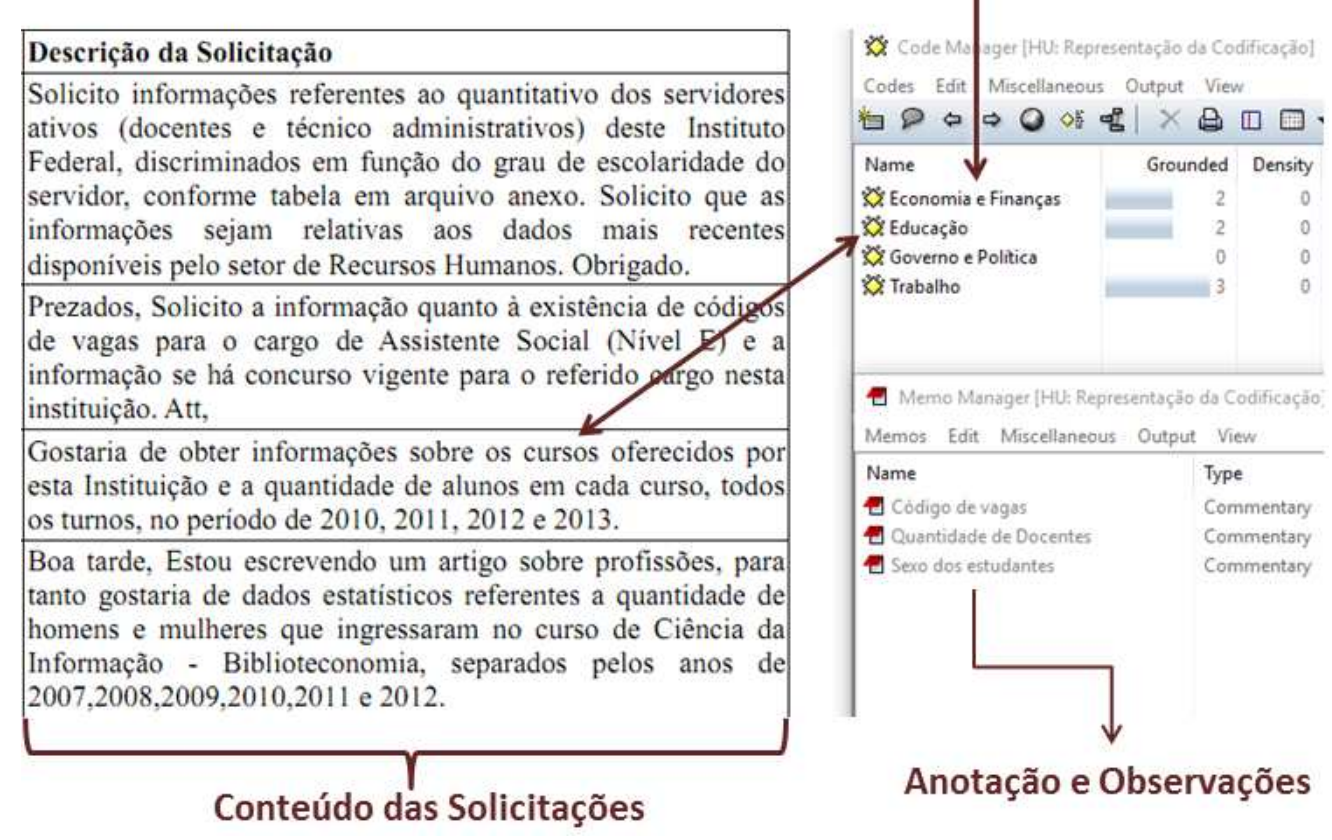

O surgimento dos códigos teve como base as repetidas solicitações, pois, segundo a Grounded Theory, quando uma informação tem as mesmas propriedades aumenta-se sua fundamentação e, caso a informação seja nova, cria-se um novo código. Várias análises foram realizadas observando o número de incidência dos temas nas solicitações. Por meio da codificação aberta foi possível identificar padrões para a criação de códigos.

$\mathrm{Na}$ fase de codificação axial, os códigos identificados foram agrupados de acordo com suas similaridades. Na relação entre os códigos e categorias foi utilizada a associação is associated with, a qual, segundo Conte et al, (2009) é utilizada quando os códigos possuem conceitos específicos relacionados.

De acordo com a metodologia, o pesquisador deve realizar a análise dos dados em busca de códigos, que para o contexto deste artigo, refere-se aos temas demandados pela sociedade, de modo que foram identificados para posterior apresentação das categorias e temas propostos.

Para cada código encontrado, foi atribuído um conjunto de dois números que representam, respectivamente, o grau de fundamentação do tema e o grau de densidade. Dessa forma, um código que possui a representação "Quantidade de Servidores $\{2-1\}$ " demonstra que possui 2 Incidências, ou seja, incidências encontradas dentro do texto avaliado, e este associado a uma categoria principal atribuída pelo pesquisador na fase de codificação seletiva.

A Figura 3 demonstra uma visão resumida de parte do processo aplicado pela metodologia Grounded Theory, envolvendo as três fases do método. 
Figura 3. Etapas da criação das categorias e temas

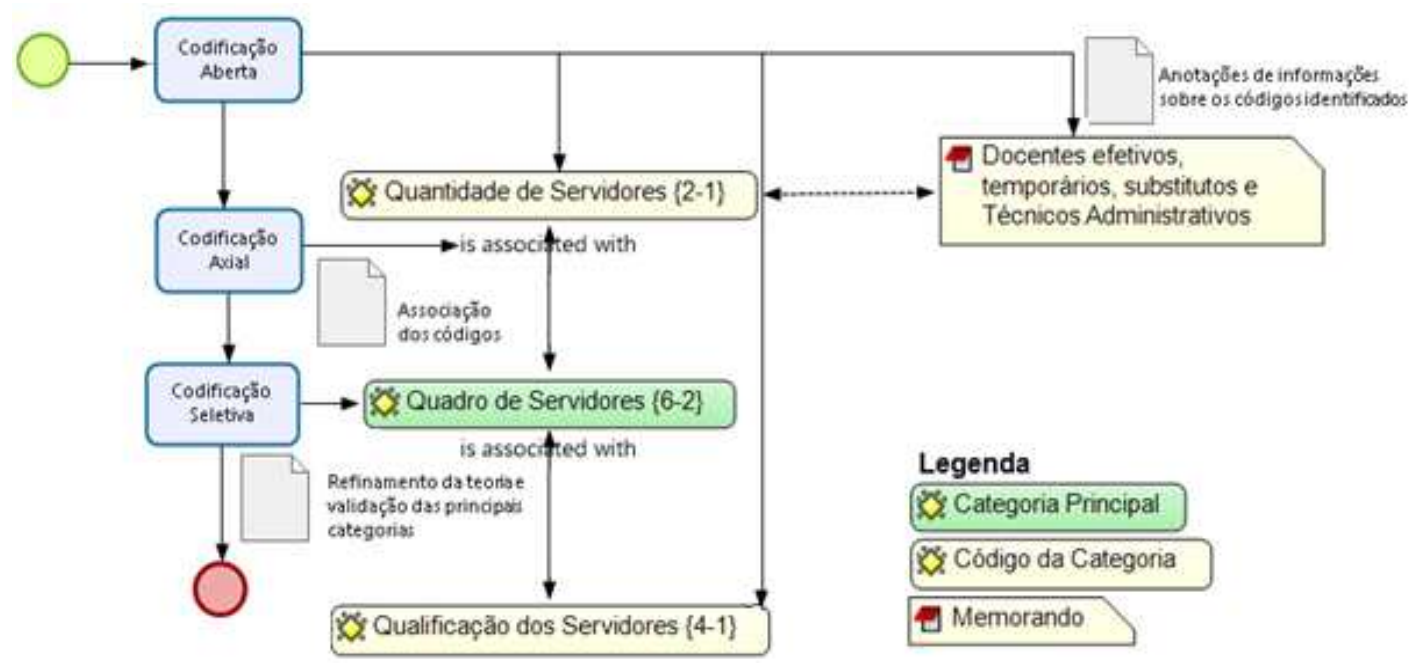

A última fase envolveu a etapa de codificação seletiva em que foram validadas as categorias principais, cujo objetivo foi representar os demais códigos encontrados na pesquisa. Os códigos e as categorias foram validados junto a um grupo focal composto por três profissionais, um ligado ao e-SIC e dois ligados a área de dados abertos.

O objetivo desta validação foi verificar se os códigos/temas identificados refletiam as demandas registradas e destacadas nos pedidos de informação e se as mesmas podem ser consideradas candidatas para disponibilização em formato de dado aberto pelas IFES. Além da validação realizada foi atribuido para cada código/tema uma classificação, indicando se apresenta potencial para ser disponibilizando em formato de dado aberto, se o mesmo se trata apenas de uma questão ligada a dados de transparência ou, se trata de dados sigilosos e requer uma análise particular de cada instituição para sua disponibilização.

Os códigos/temas que possuem a classificação DA (Dado Aberto) foram considerados prioritários e candidatos a serem disponibilizados em formato aberto. Os temas indicados pela classificação DT (Dado de Transparência) correspondem a temas que devem ser atendidos pelas instituições por meio de páginas ou portais web de acesso à informação, pois se tratam de informações não estruturadas. Os temas indicados pela classificação DS (Dado Sigiloso) representam informações que abordam dados sigilosos ou pessoais, requerem um cuidado especial para sua disponibilização e necessitam de outros mecanismos para prover acesso ao público interessado.

\section{Análise e Apresentação dos Resultados}

As categorias e os temas identificados como sendo de interesse da sociedade foram organizados em tabela, cada qual, com sua categoria e respectivos temas associados, bem como com a classificação atribuida pelo grupo focal. Com a aplicação da Grounded Theory, foram identificadas 20 categorias e 144 códigos/temas, os quais são apresentados nesta seção.

\subsection{Quadro de Servidores}

O Quadro 3 apresenta como categoria principal "Quadro de Servidores", composta por 845 incidências associadas por 12 códigos/temas. 
Quadro 3. Categoria Quadro de Servidores

\begin{tabular}{|c|c|c|c|}
\hline Categoria Principal & Temas Associados & Incidência & Classificação \\
\hline $\begin{array}{l}\text { Quadro de Servidores } \\
\text { - } 845 \text { Incidências } \\
\text { - } 12 \text { Temas associados }\end{array}$ & $\begin{array}{l}1^{\circ} \text { - Quantidade de Servidores } \\
2^{\circ} \text { - Lotação dos Servidores } \\
3^{\circ} \text { - Carga Horária dos Docentes } \\
4^{\circ} \text { - Qualificação dos Servidores } \\
5^{\circ} \text { - Funções Gratificadas } \\
6^{\circ} \text { - Função dos Servidores } \\
7^{\circ} \text { - Remuneração dos Servidores } \\
8^{\circ} \text { - Quantidade de Servidores Afastados } \\
9^{\circ} \text { - Endereço de e-mail dos Servidores } \\
10^{\circ} \text { - Horário de Trabalho } \\
11^{\circ} \text { - Servidores Temporários } \\
12^{\circ} \text { - Servidores Aposentados }\end{array}$ & $\begin{array}{c}301 \\
280 \\
66 \\
55 \\
43 \\
40 \\
39 \\
07 \\
04 \\
04 \\
02 \\
02\end{array}$ & $\begin{array}{l}\text { DA } \\
\text { DA } \\
\text { DA } \\
\text { DA } \\
\text { DA } \\
\text { DA } \\
\text { DA } \\
\text { DA } \\
\text { DA } \\
\text { DA } \\
\text { DA } \\
\text { DA }\end{array}$ \\
\hline
\end{tabular}

Por meio da aplicação da metodologia Grounded Theory os temas associados à categoria principal referem-se a solicitações relacionadas à quantidade de servidores, onde se destacam as solicitações sobre a quantidade de docentes efetivos, substitutos e técnicos administrativos em exercício na instituição, bem como suas respectivas lotações.

Outro foco das solicitações associadas à categoria vai em direção aos dados referentes à carga horária de trabalho dos profissionais, cuja principal demanda é sobre o regime de dedicação dos servidores. Demandas também foram associadas à qualificação dos profissionais, com pedidos voltados ao grau de escolaridade dos servidores.

Os temas demandados e associados a categoria também apresentam solicitações sobre a função dos servidores, com demandas acerca das atividades desenvolvidas, funções gratificadas e remuneração recebida pelo desempenho de suas atividades. Considerando que o portal de transparência já apresenta dados relacionados à remuneração dos profissionais, percebe-se que a sociedade está utilizando-se do e-SIC para obter acesso à informação que já está, de certo modo, publicada. Tal observação leva a refletir sobre o real conhecimento que a sociedade tem de tal recurso, bem como, se a informação é, ou está transparente e acessível para que a comunidade possa compreendê-la. Pois, por mais que os dados estejam disponibilizados, é necessário que a sociedade possa acessá-los e manipulá-los para atender suas distintas necessidades, e é neste sentido que os dados abertos vêm contribuir com esse processo [DINIZ, 2010].

Com uma incidência menor, estão as informações identificadas na pesquisa relacionadas à quantidade de servidores afastados, endereço de e-mails de servidores, horário de trabalho dos profissionais, quantidade de servidores temporários $\mathrm{e}$ contratados.

\subsection{Concurso Público}

No Quadro 4, observa-se que os temas identificados tiveram como foco principal informações ligadas a categoria "Concurso Público". Avaliando o conteúdo das solicitações, podemos constatar que os demandantes solicitaram informações sobre disponibilidade de vagas e possibilidade de aproveitamento em concurso público, tendo em vista a aprovação em outro certame. 
Quadro 4. Quadro de Servidores

\begin{tabular}{|l|l|c|c|}
\hline Categoria Principal & Temas Associados & Incidência & Classificação \\
\hline & $1^{\circ}$ - Código de Vaga & 397 & DA \\
& $2^{\circ}$ - Aproveitamento de Concurso & 81 & DA \\
& $3^{\circ}$ - Novos Concursos & 26 & DT \\
Concurso Público & $4^{\circ}$ - Nomeação de Aprovados & 24 & DA \\
- 577 Incidências & $5^{\circ}$ - Cronograma do Concurso & 13 & DA \\
- 10 Temas associados & $6^{\circ}$ - Provas e Gabaritos & 11 & DA \\
& $7^{\circ}$ - Prorrogação de Concurso Vigente & 10 & DA \\
& $8^{\circ}$ - Distribuição das Vagas - Cotas & 06 & DA \\
& $9^{\circ}$ - Questionamentos & 06 & DT \\
& $10^{\circ}$ - Requisitos para o Cargo & 03 & DA \\
\hline
\end{tabular}

Demandas também foram identificadas relacionadas à busca pela sociedade de informações sobre a previsão de realização de novos concursos e a disponibilização/localização das provas e gabaritos de concursos anteriores.

Alguns dos temas identificados foram relacionados a solicitações cuja finalidade estava direcionada a: nomeações de aprovados, solicitações acerca da data de nomeação de candidatos classificados; cronograma do concurso, demandas sobre datas de aplicação de provas e demais fases do processo; prorrogação de concurso vigente com consultas junto às instituições sobre a possibilidade de prorrogação de concursos já realizados; distribuição das vagas - cotas, pedidos de informação acerca do procedimento utilizado pela instituição para distribuição das vagas; questionamentos registrados por cidadãos sobre notas obtidas por outros candidatos (concorrentes) em concurso, bem como critérios utilizados para aplicação de desempates e requisitos para o cargo, em que o objetivo visava esclarecimentos sobre determinadas formações (certificados) para assumir vagas de concurso em caso de aprovação.

\subsection{Pesquisas Acadêmicas}

A categoria "Pesquisas Acadêmicas" apresentada no Quadro 5 teve 481 incidências e 15 temas associados, composta por demandas que buscavam informações para subsidiar o desenvolvimento de pesquisas acadêmicas.

Quadro 5. Pesquisas Acadêmicas

\begin{tabular}{|c|c|c|c|}
\hline Categoria Principal & Temas Associados & Incidência & Classificação \\
\hline $\begin{array}{l}\text { Pesquisas } \\
\text { Acadêmicas } \\
\text { - } 481 \text { Incidências } \\
\text { - } 15 \text { Temas associados }\end{array}$ & $\begin{array}{l}1^{\circ} \text { - e-SIC } \\
2^{\circ} \text { - Administração Pública } \\
3^{\circ} \text { - Alunos } \\
4^{\circ} \text { - Quadro de Servidores } \\
5^{\circ} \text { - Cursos } \\
6^{\circ} \text { - Servidores com Deficiência } \\
7^{\circ} \text { - Preenchimento de Anexo } \\
8^{\circ} \text { - Gestão de Pessoas } \\
9^{\circ} \text { - Depreciação de Patrimônio } \\
10^{\circ} \text { - Transparência da IFES } \\
11^{\circ} \text { - Orçamento } \\
12^{\circ} \text { - Acessibilidade } \\
13^{\circ} \text { - Servidores Terceirizados } \\
14^{\circ} \text { - Disponibilidades para Entrevistas } \\
15^{\circ} \text { - Licitação }\end{array}$ & $\begin{array}{l}162 \\
58 \\
54 \\
35 \\
26 \\
23 \\
20 \\
19 \\
15 \\
14 \\
13 \\
12 \\
12 \\
10 \\
08 \\
\end{array}$ & $\begin{array}{l}\text { DA } \\
\text { DA } \\
\text { DA } \\
\text { DA } \\
\text { DA } \\
\text { DA } \\
\text { DT } \\
\text { DT } \\
\text { DA } \\
\text { DT } \\
\text { DA } \\
\text { DT } \\
\text { DA } \\
\text { DT } \\
\text { DA }\end{array}$ \\
\hline
\end{tabular}

Percebe-se que muitas das solicitações estavam ligadas ao tema e-SIC cujos objetivos das solicitações eram: obter dados acerca da quantidade de pedidos encaminhados ao órgão, jornada de trabalho, formação e cargo dos servidores 
responsáveis pelo e-SIC, fluxo de atendimento e o nível de capacitação dos servidores que atuam no setor.

O grande número de incidências encontradas nesse tema aponta para uma possível preocupação da sociedade em fiscalizar e acompanhar o atendimento da LAI nas instituições, bem como verificar o fluxo e o processo desenvolvido pelas IFES para atender as demandas da sociedade.

O tema "Administração Pública", representado no Quadro, demonstra essa necessidade já manifestada pela sociedade, a qual requer das instituições relatórios de gestão entre outros documentos de caráter público para acompanhamento e fiscalização.

Vários temas identificados no corpo das solicitações revelam a busca de dados referentes a alunos da instituição solicitando informações sobre o número de matrículas, sexo dos alunos, naturalidade, índices de evasão, número de alunos portadores de deficiência, de alunos concluintes e questões relativas à utilização de nomes sociais utilizados pelos estudantes nas instituições.

Demandas relacionadas ao quadro de servidores, quantidade de servidores com deficiência e cursos ofertados pela instituição também tiveram uma grande representação nessa categoria. Algumas das solicitações demandadas às IFES buscavam a colaboração dos servidores para preenchimento de anexos e disponibilidade para realização de entrevistas.

Avaliando o tema das solicitações como um todo, verificou-se que muitas solicitações remetem a temas similares, já atendidos em momentos anteriores. Entretanto, algumas solicitações acabam demandando mais tempo/recursos para ser atendida, por se tratar de demandas específicas.

Analisando os conteúdos dessas demandas, infere-se que a dificuldade relacionada ao atendimento não está associado à complexidade dos pedidos e sim, ao trabalho requerido para atender as especificidades das demandas, tendo em vista a limitação de profissionais, sistemas e tempo para atendimento das solicitações.

Destacaram-se como pedidos específicos as demandas por informações relacionadas à gestão de pessoas, em que os demandantes solicitaram informações sobre o procedimento utilizado pela instituição para alocação dos servidores nos setores; situação do patrimônio, onde os demandantes buscam informações acerca da depreciação dos bens públicos; sobre transparência da IFES, com questionamentos sobre ações tomadas pela instituição para ampliar a prestação de contas junto à comunidade. Algumas solicitações buscam avaliar também o nível de transparência do ponto de vista do servidor respondente e demandas acerca da acessibilidade (física e virtual) nos ambientes da instituição para ter acesso a informações públicas.

\subsection{Administração Pública}

A categoria "Administração Pública" teve um total de 311 incidências, com sete temas associados, abrangendo solicitações relacionadas a documentos institucionais, tais como: regimento da instituição, portarias e resoluções expedidas pela instituição; acesso a informações contidas em atas de reuniões, destacando a necessidade da disponibilização de cópias, lista de participantes e disponibilização de vídeos das reuniões e relação de convênios firmados, contendo data de assinatura e período de vigência dos convênios. 
Quadro 6. Administração Pública

\begin{tabular}{|l|l|c|c|}
\hline \multicolumn{1}{|c|}{ Categoria Principal } & Temas Associados & Incidência & Classificação \\
\hline & $1^{\mathbf{o}}$ - Documentos Institucionais & 156 & DA \\
& $2^{\text {o }}$ - Atas de reuniões & 48 & DA \\
Administração Pública & $3^{\text {o }}$ - Politica de Gestão de Documentos & 39 & DT \\
- 311 Incidências & $4^{\mathbf{o}}$ - Organograma da IFES & 24 & DA \\
- 7 Temas associados & $5^{\text {o }}$ - Manuais de Fiscalização & 18 & DA \\
& $6^{\mathbf{o}}$ - Convênios Firmados & 11 & DA \\
& $7^{\mathbf{o}}$ - Relatórios de Auditorias & 05 & DA \\
\hline
\end{tabular}

Percebe-se no Quadro 6, que os temas solicitados apresentam demandas diversificadas de informações associadas à administração pública, bem como, sobre procedimentos adotados pela instituição para com a gestão destes documentos e fiscalização como um todo.

Durante a avaliação dos pedidos, perceberam-se temas ligados à política de gestão de documentos, com pedidos sobre o procedimento realizado para catalogação e organização das informações nas instituições, sobre seus responsáveis e tipo de capacitação que os servidores receberam para exercer a referida função.

Questões ligadas à fiscalização também são foco das demandas. Nelas, os solicitantes buscam acesso a manuais adotados pelas IFES para fiscalização de contratos e procedimentos administrativos, bem como relatórios de auditorias como os planos de trabalhos elaborados para tal finalidade. Existem também solicitações relacionadas a acesso ao organograma das instituições.

\subsection{Cursos}

A categoria "Cursos" teve 259 incidências e 11 temas associados, contendo demandas sobre número de alunos por curso; cursos ofertados pela instituição e turnos oferecidos; quantidade de vagas oferecidas por curso; carga horária das disciplinas; PPCs de cursos; grade curricular com solicitações acerca das disciplinas contidas nos cursos oferecidos; cronograma das aulas em que as solicitações demandaram acesso detalhado do planejamento das aulas e tarefas a serem repassadas pelos professores aos estudantes.

Quadro 7. Categoria Cursos

\begin{tabular}{|c|c|c|c|}
\hline Categoria Principal & Temas Associados & Incidência & Classificação \\
\hline $\begin{array}{l}\text { Cursos } \\
\text { - } 259 \text { Incidências } \\
\text { - } 11 \text { Temas associados }\end{array}$ & $\begin{array}{l}1^{\circ} \text { - Número de Alunos por Curso } \\
2^{\circ} \text { - Cursos Ofertados } \\
3^{\circ} \text { - Quantidade de Vagas } \\
4^{\circ} \text { - Carga Horária das Disciplinas } \\
5^{\circ} \text { - PPCs de Cursos } \\
6^{\circ} \text { - Grade Curricular } \\
7^{\circ} \text { - Quantidade de Matrículas } \\
8^{\circ} \text { - Previsão de Novos Cursos } \\
9^{\circ} \text { - Pronatec } \\
10^{\circ} \text { - Custo por Aluno } \\
11^{\circ} \text { - Cronograma das Aulas }\end{array}$ & $\begin{array}{l}71 \\
47 \\
35 \\
33 \\
28 \\
23 \\
08 \\
05 \\
03 \\
03 \\
03\end{array}$ & $\begin{array}{l}\text { DA } \\
\text { DA } \\
\text { DA } \\
\text { DA } \\
\text { DA } \\
\text { DA } \\
\text { DA } \\
\text { DT } \\
\text { DA } \\
\text { DA } \\
\text { DA }\end{array}$ \\
\hline
\end{tabular}

Os temas representados pelos temas correspondem à maioria das solicitações relacionadas a "Educação". Ainda que o objetivo deste trabalho não seja de avaliar se as instituições disponibilizam estas informações em seus portais, ou se atendem às orientações dispostas na LAI, tal resultado permite inferir que as instituições necessitam publicar informações pertinentes aos dados de cursos, visto que promover a transparência é uma forma de educar o cidadão, função social da educação. 
Alguns temas identificados nesta categoria buscaram acesso à quantidade de matrículas realizadas pela instituição a cada ano, previsão de novos cursos a serem ofertados na instituição; custo por aluno, onde as solicitações relacionaram-se ao valor médio investido pela instituição com cada aluno e informações sobre programas oferecidos por ela.

\subsection{Alunos}

No Quadro 8 é apresentada a categoria "Alunos" com 229 incidências e seis temas associados. As solicitações buscavam obter acesso a dados sobre a quantidade de estudantes da instituição, levando em consideração todos os programas ofertados. Temas identificados na categoria, também compreendem informações relacionadas ao índice de abandonos nos cursos, onde as demandas tiveram como objetivo obter informações sobre o número de evasão de estudantes; matrículas trancadas, com demandas sobre o motivo e o número de trancamentos; quantidade de reprovações por curso, por notas e por frequência; quantidade de alunos formados; e quantidade de bolsistas contratados. Já as demandas estavam relacionadas à remuneração recebida e atividades desenvolvidas pelos estudantes nas instituições e nos projetos vinculados.

Quadro 8. Categoria Alunos

\begin{tabular}{|l|l|c|c|}
\hline \multicolumn{1}{|c|}{ Categoria Principal } & Temas Associados & Incidência & Classificação \\
\hline & $1^{\mathbf{o}}$ - Quantidade de Estudantes & 116 & DA \\
Alunos & $2^{\mathbf{o}}$ - Quantidade de Abandonos & 49 & DA \\
- 229 Incidências & $3^{\text {o }}$ - Matrículas Trancadas & 29 & DA \\
- 6 Temas associados & $4^{\text {o }}$ Alunos Formados & 25 & DA \\
& $5^{\text {o }}$ - Quantidade de Bolsistas & 07 & DA \\
& $6^{\mathbf{o}}$ - Quantidade de Reprovações & 03 & DA \\
\hline
\end{tabular}

Os resultados reforçam que a disponibilização de dados em formato aberto pelas IFES é fundamental para proporcionar inovação no setor público. Muitas soluções podem ser desenvolvidas pela sociedade com objetivos de intervir antecipadamente em determinados problemas, mas, para isso, é preciso proporcionar à sociedade, informações relevantes, íntegras e atuais para que soluções possam vir a ser encontradas.

\subsection{Assistência ao Estudante}

Com 211 incidências, a categoria "Assistência ao Estudante" teve cinco temas associados, com solicitações sobre o tipo de auxílio concedido pelas instituições, valor dos benefícios disponibilizados aos estudantes, informações sobre gastos com o programa, com solicitações acerca de informações sobre o valor aplicado anualmente ao programa, quantidade de beneficiados, sobre o número de bolsas concedidas e critérios de seleção adotados pela instituição para concessão de bolsa aos estudantes.

Quadro 9. Categoria Assistência ao Estudante

\begin{tabular}{|l|l|c|c|}
\hline \multicolumn{1}{|c|}{ Categoria Principal } & Temas Associados & Incidência & Classificação \\
\hline & $1^{\circ}-$ Tipo de Auxilio & 74 & DA \\
Assistência ao Estudante & $2^{\circ}$ - Gastos com o Programa & 70 & DA \\
- 211 Incidências & $3^{\circ}$ - Quantidade de Beneficiados & 45 & DA \\
- 5 Temas associados & $4^{\text {o }}$ Pagamento de Bolsas & 18 & DA \\
& $5^{\circ}$ - Critérios de Seleção & 04 & DT \\
\hline
\end{tabular}

Algumas das solicitações relacionadas à categoria principal buscavam informações sobre a regularização dos pagamentos de bolsas, onde se pode perceber pedidos acerca do motivo dos atrasos nos pagamentos de bolsas. 


\subsection{Licitação}

Quanto à categoria "Licitação", verificou-se 206 incidências oriundas de cinco temas associados. Nessa categoria, as solicitações visavam acesso a informações sobre empresas vencedoras de licitações (fornecedores), como por exemplo: a necessidade de informações sobre datas de vigência de editais, valores de contratos, equipamentos fornecidos, bem como sobre empresas prestadoras de serviço, com demandas relacionadas aos tipos de serviços prestados, envolvendo serviços como manutenção predial e vigilância.

Quadro 10. Categoria Licitação

\begin{tabular}{|l|l|c|c|}
\hline \multicolumn{1}{|c|}{ Categoria Principal } & \multicolumn{1}{|c|}{ Temas Associados } & Incidência & Classificação \\
\hline & $1^{\circ}$ - Fornecedores & 85 & DA \\
Licitação & $2^{\text {o }}$ - Contratos de Prestação de Serviço & 79 & DA \\
- 206 Incidências & $3^{\text {o }}$ Informações sobre Contratos & 35 & DA \\
- 5 Temas associados & $4^{\text {o }}$ - Valor de Aluguéis cobrados & 04 & DA \\
& $5^{\text {o }}$ - Compras Sustentáveis & 03 & DT \\
\hline
\end{tabular}

Craveiro, Santana e Alburquerque (2013) apontam para a existência de uma grande inconformidade quanto à publicação de dados que envolvem orçamento, chamando a atenção para o fato de que as informações atendem apenas parcialmente alguns dos princípios dos dados abertos e que as informações são publicadas com muito atraso, ou seja, os dados não são atualizados com rigor. Além disso, é importante salientar que as informações relacionadas a licitações são complexas e requerem um grande conhecimento por parte da sociedade para compreender a estrutura e conteúdo desses documentos, fato este que pode ser simplificado com a disponibilização de dados em formatos abertos, em que a sociedade, por meio de ferramentas e soluções informatizadas pode construir novas formas de visualização dessas informações.

Outro tema que teve destaque na categoria foram os contratos firmados pela instituição, refletindo a busca por informações relacionadas a dados como número de editais e de contratos de locação de imóveis contratados para funcionamento de determinadas unidades da instituição. Além do mais, algumas solicitações tinham como objetivo obter informações sobre os valores de aluguéis cobrados pelas IFES a empresas que exploram áreas públicas dentro das instalações públicas, como, cantina, restaurantes universitários e centros de reprografia. Ainda ligadas à categoria principal, pode-se observar dentre as informações apresentadas, pedidos associados a compras sustentáveis, demonstrando a necessidade de informações acerca de critérios considerados pelas instituições para a realização de compras sustentáveis em seus processos licitatórios.

\subsection{Validação de Diplomas}

Esta categoria teve 153 incidências e cinco temas associados, nos quais as solicitações registradas relacionaram-se à revalidação de diplomas, cujos solicitantes buscavam informações sobre quais cursos a instituição estava apta a validar. Algumas solicitações buscavam também obter orientações sobre os procedimentos para validação de diplomas e reconhecimentos de títulos, com solicitações partindo de cidadãos interessados em revalidar certificados de cursos junto à instituição. 
Quadro 11. Categoria Validação de Diplomas

\begin{tabular}{|c|c|c|c|}
\hline Categoria Principal & Temas Associados & Incidência & Classificação \\
\hline $\begin{array}{l}\text { Validação de Diplomas } \\
\text { - } 153 \text { Incidências } \\
\text { - } 5 \text { Temas associados }\end{array}$ & $\begin{array}{l}1^{\circ} \text { - Revalidação de Diplomas } \\
2^{\circ} \text { - Procedimentos para Validação } \\
3^{\circ} \text { - Quantidade de Validações } \\
4^{\circ} \text { - Reconhecimento de Títulos } \\
5^{\circ} \text { - Situação de Validações }\end{array}$ & $\begin{array}{l}77 \\
27 \\
26 \\
21 \\
02\end{array}$ & $\begin{array}{l}\text { DA } \\
\text { DA } \\
\text { DA } \\
\text { DA } \\
\text { DT }\end{array}$ \\
\hline
\end{tabular}

As solicitações avaliadas, também mostram que as demandas relacionavam-se à quantidade de validações realizadas pela instituição e, em alguns casos, a situação de determinadas validações encaminhadas à instituição, ou seja, aos detalhes sobre os motivos de indeferimento de títulos submetidos para revalidação.

\subsection{Obras}

No Quadro 12 é apresentada a categoria "Obras", que teve 114 incidências com três temas associados. As demandas identificadas foram relacionadas a temas ligados a quantidade de obras em andamento, período de conclusão das obras e custo por obra, em que as demandas buscavam informações sobre o valor investido.

Quadro 12. Categoria Obras

\begin{tabular}{|c|c|c|c|}
\hline Categoria Principal & Temas Associados & Incidência & Classificação \\
\hline Obras & $1^{\circ}$ - Obras em Andamento & 58 & DA \\
\hline - 114 Incidências & $2^{\circ}$ - Conclusão de Obras & 50 & DA \\
\hline - 3 Temas associados & $3^{\circ}-$ Custo por Obras & 06 & DA \\
\hline
\end{tabular}

As solicitações ligadas ao tema "Conclusão de obras" também demandaram informações acerca de possíveis paralisações ocorridas durante a realização das obras, seus respectivos motivos e prazo programado para entrega.

\subsection{Patrimônio}

Percebe-se no Quadro 13, a presença de quatro temas associados à categoria principal, "Patrimônio", a qual teve 103 incidências. Os temas identificados tiveram como objetivo obter acesso a informações sobre a frota de veículos das IFES, com dados relacionados à quantidade de veículos, marca, ano, modelo, quilometragem, gastos com combustível e responsáveis pela frota.

\section{Quadro 13. Categoria Patrimônio}

\begin{tabular}{|l|l|c|c|}
\hline \multicolumn{1}{|c|}{ Categoria Principal } & Temas Associados & Incidência & Classificação \\
\hline Patrimônio & $1^{\text {o }}$ - Frota de Veículos & 72 & DA \\
- 103 Incidências & $2^{\text {o }}$ - Administração Patrimonial & 19 & DT \\
- 4 Temas associados & $3^{\text {o }}$ - Lista de equipamentos & 09 & DA \\
& $4^{\text {o }}$ - Manutenção de Equipamentos & 03 & DA \\
\hline
\end{tabular}

Informações relacionadas à administração patrimonial também foram demandadas, cujo objetivo foi obter informações sobre depreciação dos bens públicos, enquanto outras buscavam acesso a informações ligadas à lista de equipamentos (tipos de equipamentos e quantidades) bem como procedimentos adotados pelas instituições quanto a cronograma de manutenções.

\subsection{Dúvidas de Servidores}

Durante a análise dos pedidos de informação foi possível perceber um grande número de solicitações partindo de servidores públicos federais em busca de informações relacionadas a esclarecimento de dúvidas. Tendo em vista a grande incidência desse 
assunto, criou-se uma categoria chamada "Dúvidas de Servidores", a qual teve 86 Incidências e nove temas associados.

Quadro 14. Categoria Dúvidas de Servidores

\begin{tabular}{|l|l|c|c|}
\hline Categoria Principal & Temas Associados & Incidência & Classificação \\
\hline & $1^{\circ}$ - Modalidades de Licitação & 36 & DA \\
& $2^{\circ}$ - Dúvidas Gerais & 15 & DT \\
Dúvidas de & $3^{\circ}$ - Acesso a Contracheques & 10 & DS \\
Servidores & $4^{\text {o }}$ - Organização do e-SIC na IFES & 08 & DT \\
- 86 Incidências & $5^{\circ}$ - Estruturar Processo de Redistribuição & 05 & DT \\
- 9 Temas associados & $6^{\circ}$ - Dados de Acesso & 05 & DS \\
& $7^{\text {o }}$ Participação em Eventos & 03 & DT \\
& $8^{\circ}$ - Progressão de Servidores & 02 & DA \\
& $9^{\circ}$ - Implantação de Sistemas & 02 & DT \\
\hline
\end{tabular}

Entre os assuntos mais solicitados destaca-se o tema relacionado a modalidades de licitações, cujo objetivo das demandas era informações sobre os tipos de licitações adotadas pelas instituições para contratação de determinados serviços/empresas. Outros tratavam de dúvidas gerais sobre procedimentos para encaminhamento de aposentadoria, informações sobre valor de salário, procedimentos para agendamento de férias, formas para acesso a empréstimos consignados e carga horária de trabalho dos servidores.

Informações ligadas à estruturação do e-SIC nas IFES também foram foco das solicitações, com pedidos de informações sobre como o serviço foi implantado e está sendo atendido pelas instituições, além de participação em eventos e implantação de sistemas nas quais os solicitantes buscaram orientações acerca da disponibilização de recursos financeiros para custear a participação em eventos, e dúvidas sobre funcionalidades dos novos sistemas (softwares) implantados pela instituição.

O foco dos pedidos apresentados nesta categoria indica haver uma carência, ou até mesmo um desconhecimento dos processos institucionais por parte dos servidores. Fato esse que poderia ser minimizado se instituições realizassem mais capacitações com seus profissionais, como por exemplo, sobre estruturação de processo de redistribuição e progressão de servidores, assunto identificado em dúvidas registradas sobre documentos necessários para encaminhamento dos processos administrativos.

\subsection{Despesas}

No Quadro 15 é apresentada a categoria "Despesas" com 83 incidências e 10 temas associados, onde os solicitantes buscavam informações como, quantidade de profissionais terceirizados e valores pagos; gastos com consumo de energia elétrica nas instalações das IFES; quantidade e valor de diárias e passagens pagas pela instituição; prestação de contas das despesas, onde os demandantes requeriam acesso a relatórios de gestão dos anos anteriores; despesas com água; gastos com a realização de eventos e congressos organizados pela instituição; gastos por programa, em que destacavam a necessidade de acesso ao montante de recurso destinado a cada programa; valores gastos com telefone e despesas realizadas com cartão corporativo da instituição.

Quadro 15. Categoria Despesas

\begin{tabular}{|l|l|c|c|}
\hline Categoria Principal & Temas Associados & Incidência & Classificação \\
\hline & $1^{\circ}$ - Profissionais Terceirizados & 20 & DA \\
& $2^{\circ}-$ Energia Elétrica & 14 & DA \\
Despesas & $3^{\text {o }}$ Despesas Gerais da IFES & 10 & DA \\
-83 Incidências & $4^{\text {o }}$ Diárias e Passagens & 08 & DA \\
\hline
\end{tabular}




\begin{tabular}{|c|l|c|c|}
\hline Categoria Principal & Temas Associados & Incidência & Classificação \\
\hline-10 Temas associados & $5^{\text {o }}$ - Prestação de Contas & 07 & DA \\
& $6^{\circ}$ - Água & 05 & DA \\
& $7^{\text {o }}$ Eventos e Congressos & 04 & DA \\
& $8^{\circ}$ - Gastos por Programa & 04 & DA \\
& $9^{\circ}-$ Telefone & 04 & DA \\
& $10^{\circ}$ - Cartão Corporativo & 03 & DA \\
\hline
\end{tabular}

\subsection{Documentos Pessoais}

A análise do conteúdo das solicitações identificou pedidos demandados por servidores públicos federais, em que foi solicitado acesso a cópia de documentos pessoais registrados no setor de recursos humanos e comprovantes de rendimento, onde os solicitantes requeriam acesso a extratos dos salários recebidos. Solicitações partindo de estudantes estavam relacionadas a obter acesso a cópias de certificados do ENEM.

Quadro 16. Documentos Pessoais

\begin{tabular}{|l|l|c|c|}
\hline \multicolumn{1}{|c|}{ Categoria Principal } & \multicolumn{1}{|c|}{ Temas Associados } & Incidência & Classificação \\
\hline & $1^{\circ}-$ Cópia de Documentos & 43 & DS \\
Documentos Pessoais & $2^{\text {o }}$ - Comprovante de Rendimento & 11 & DS \\
- 67 Incidências & $3^{\text {o }}$ - Certificado do ENEM & 05 & DS \\
- 6 Temas associados & $4^{\text {o }}$ Andamento da Redistribuição & 04 & DS \\
& $5^{\text {o }}$ - Situação da Progressão & 02 & DS \\
& $6^{\text {o }}$ - Declaração de Participação em Banca & 02 & DS \\
\hline
\end{tabular}

As solicitações também focalizaram assuntos relacionados ao andamento de redistribuição de determinados servidores, de processos de progressão, bem como assuntos ligados à disponibilização de declaração de participação em bancas de avaliações.

Denis et al. (2014), destaca que a disponibilização de dados requer etapas fundamentais, que envolvem desde a exploração dos dados que serão disponibilizados, a extração dessas informações dos sistemas utilizados pelas instituições até a ramificação dos dados, etapa que consiste na limpeza das informações para não liberar dados sigilosos.

\subsection{Infraestrutura}

$\mathrm{Na}$ categoria "Infraestrutura", foram identificadas 66 Incidências e cinco temas associados. Os temas representados no Quadro estão relacionados a pedidos onde os demandantes buscaram informações sobre infraestrutura das instituições, com demandas acerca do número total de vagas de estacionamento, total de área construída, quantidade de ambientes como salas de aulas e laboratórios, quantidade de restaurantes universitários e infraestrutura para deficientes, e as solicitações buscavam informações sobre o nível de adequação das instituições para atender pessoas com deficiências.

\section{Quadro 17. Infraestrutura}

\begin{tabular}{|l|l|c|c|}
\hline \multicolumn{1}{|c|}{ Categoria Principal } & Temas Associados & Incidência & Classificação \\
\hline & $1^{\mathbf{o}}$ - Vagas de Estacionamento & 19 & $\mathrm{DA}$ \\
Infraestrutura & $2^{\mathbf{o}}$ - Área Construída & 18 & $\mathrm{DA}$ \\
- 66 Incidências & $3^{\mathbf{o}}$ - Quantidade de Ambientes & 14 & $\mathrm{DA}$ \\
- 5 Temas associados & $4^{\mathbf{o}}$ - Qtd de Restaurantes Universitários & 13 & DA \\
& $5^{\mathbf{o}}$ - Infraestrutura para Deficientes & 02 & $\mathrm{DT}$ \\
\hline
\end{tabular}

A disponibilização de dados abertos acerca de informações relacionadas à infraestrutura das IFES pode despertar vários interesses. Muitas vezes, a sociedade 
desconhece a infraestrutura oferecida pelas IFES. A transparência de informações acerca das instalações, infraestrutura física, pode fomentar a realização de projetos e parcerias com empresas privadas por meio de projetos de pesquisas, com intuito de desenvolver soluções ou testar produtos que, até então, para empresas que enfrentam dificuldades em relação a limitações tecnológicas, tanto para realização de testes como validação de protótipos.

\subsection{Orçamento}

Solicitações relacionadas ao orçamento das instituições também foram foco das demandas da sociedade. Entre as solicitações analisadas, foram identificadas 56 incidências e três temas associados à categoria "Orçamento", em que as solicitações tratavam de assuntos ligados à divisão do orçamento, formas de distribuição entre as áreas de atuação da instituição, bem como a origem do orçamento (recursos financeiros) e finalidades desses investimentos.

Algumas das solicitações tiveram como objetivo obter informações acerca dos valores repassados por meio de emendas parlamentares, como: valores recebidos, quem o repassou e qual foi o destino desses investimentos.

Quadro 18. Categoria Orçamento

\begin{tabular}{|l|l|c|c|}
\hline \multicolumn{1}{|c|}{ Categoria Principal } & Temas Associados & Incidência & Classificação \\
\hline Orçamento & $1^{\circ}$ - Divisão do Orçamento & 40 & DA \\
- 56 Incidências & $2^{\text {o }}$ - Origem do Orçamento e Finalidades & 13 & DA \\
-3 Temas associados & $3^{\circ}$ - Orçamento Emendas Parlamentares & 03 & DA \\
\hline
\end{tabular}

Conforme apresentado por Craveiro et al. (2013), as informações relacionadas a orçamento público são publicadas pelas instituições em detrimento de várias exigências jurídicas vigentes no país. Além disso, as informações publicadas apresentam restrições, tanto relacionadas à questão de licença, quanto ao formato de dados disponibilizados, impedindo, dessa forma, o tratamento automatizado dessas informações segundo princípios dos dados abertos.

\subsection{Projetos de Pesquisa}

No Quadro 19, visualiza-se a categoria "Projeto de Pesquisa". A categoria teve 44 incidências e cinco temas associados. Elas versaram sobre temas relacionados a informações sobre quantidade de patentes registradas, bem como conteúdos desses registros.

Quadro 19. Categoria Projetos de Pesquisa

\begin{tabular}{|l|l|c|c|}
\hline Categoria Principal & Temas Associados & Incidência & Classificação \\
\hline & $1^{\mathbf{o}}$ - Quantidade de Patentes & 28 & DA \\
Projetos de Pesquisa & $2^{\mathbf{o}}$ - Informações sobre Projetos & 06 & DA \\
- 44 Incidências & $3^{\mathbf{o}}$ - Grupos de Pesquisa & 05 & DA \\
- 5 Temas associados & $4^{\mathbf{o}}$ - Parceiras de Pesquisa & 03 & DA \\
& $5^{\mathbf{o}}$ - Royalties de Pesquisas & 02 & DA \\
\hline
\end{tabular}

De acordo com o art. $7^{\mathrm{a}}$ da LAI, informações relacionadas a projetos de pesquisa não compreendem o rol mínimo de informações a serem disponibilizadas pelas instituições, por conterem informações de segredo industrial ou até mesmo por se tratarem de dados de segurança da sociedade e do Estado, fato este que justifica a negação do acesso à informação. Entretanto, pode-se observar no Quadro que algumas solicitações não carecem de sigilo, por não dizerem respeito a informações sigilosas, e sim públicas, cuja divulgação faz parte da transparência pública. Entre elas, destacam- 
se: pedidos de informação sobre períodos de execução dos projetos, quantidade de bolsas de estudo concedidas, natureza dos recursos, resultados alcançados, artigos publicados e relatórios de prestação de contas.

Os solicitantes também buscaram obter informações sobre a estrutura dos grupos de pesquisa em funcionamento nas IFES, informações como: servidores envolvidos em pesquisa, carga horária destinada aos projetos, parcerias firmadas com empresas privadas para a execução de pesquisas e retorno desses projetos, cujo objetivo foi obter dados sobre questões financeiras (benefícios) provenientes de royalties de projetos desenvolvidos pela instituição.

\subsection{Esclarecimentos}

A categoria "Esclarecimentos" apresenta 37 incidências e nove temas associados. As informações apresentadas no Quadro 20 demonstram os temas abordados nas solicitações em que os solicitantes buscavam respostas a questões específicas. Entre as demandas identificadas, observamos a solicitação de acesso a conteúdos de determinados documentos, assim como do número de protocolo para identificação.

Quadro 20. Categoria Esclarecimentos

\begin{tabular}{|l|l|c|c|}
\hline Categoria Principal & \multicolumn{1}{|c|}{ Temas Associados } & Incidência & Classificação \\
\hline & $1^{\mathbf{o}}$ - Teor de Determinados Documentos & 20 & DT \\
& $2^{\mathbf{o}}$ - Infraestrutura & 04 & DA \\
& $3^{\mathbf{o}}$ - Penalidade de Empresa & 02 & DA \\
Esclarecimentos & $4^{\mathbf{o}}$ - Prazo para Lançar Notas & 02 & DT \\
- 37 Incidências & $5^{\mathbf{o}}$ - Reuniões Remarcadas & 02 & DT \\
- 9 Temas associados & $6^{\mathbf{0}}$ - Metodologias de Avaliação & 02 & DT \\
& $7^{\mathbf{0}}$ - Emissão de Certificados & 02 & DT \\
& $8^{\mathbf{o}}$ - Acumulação de Cargo Público & 01 & DT \\
& $9^{\mathbf{o}}$ - Reuniões Canceladas & DT \\
\hline
\end{tabular}

Alguns solicitantes também utilizaram do canal de acesso à informação para questionar assuntos relacionados à infraestrutura das instituições. Questões ligadas a problemas como vazamento de água e mau funcionamento de climatizadores foram foco das demandas.

Solicitações ligadas à categoria que apresentaram uma incidência menor, porém não menos importante, requeria das instituições esclarecimentos acerca de motivos que levaram ao impedimento (penalidades) de determinadas empresas de participar de licitações da instituição; prazos para os professores lançarem notas dos estudantes no sistema acadêmico da instituição; metodologias de avaliação adotadas pelos professores, envolvendo critérios considerados para avaliação; demora em fornecer certificados de conclusão de cursos a estudantes; esclarecimentos sobre acumulação de cargos públicos por determinados servidores, bem como motivos de reuniões remarcadas ou canceladas pela direção.

\subsection{Dúvidas de Estudantes}

A partir das análises, foram identificados conteúdos encaminhados por estudantes relatando dúvidas relacionadas à instituição. Sendo assim, a categoria "Dúvidas de Estudante", que teve 20 incidências e oito temas associados, ilustrada pelo Quadro 21 revela essas demandas. Que se referem a procedimentos para transferência de cursos, a processos de inscrição, requisitos para acesso em cursos e relação alunolvaga (concorrência). 
Quadro 21. Dúvidas de Estudantes

\begin{tabular}{|c|c|c|c|}
\hline Categoria Principal & Temas Associados & Incidência & Classificação \\
\hline $\begin{array}{l}\text { Dúvida de Estudantes } \\
\text { - } 20 \text { Incidências } \\
\text { - } 8 \text { Temas associados }\end{array}$ & $\begin{array}{l}1^{\circ} \text { - Transferência de Curso } \\
2^{\circ} \text { - Concorrência em Cursos } \\
3^{\circ} \text { - Processo de Inscrição } \\
4^{\circ} \text { - Requisito para Acesso a Cursos } \\
5^{\circ} \text { - Curso sobre LAI } \\
6^{\circ} \text { - Locais de Prova } \\
7^{\circ} \text { - Histórico Escolar } \\
8^{\circ} \text { - Comprovante de Matrícula }\end{array}$ & $\begin{array}{l}08 \\
03 \\
03 \\
02 \\
01 \\
01 \\
01 \\
01\end{array}$ & $\begin{array}{l}\text { DT } \\
\text { DA } \\
\text { DT } \\
\text { DA } \\
\text { DT } \\
\text { DA } \\
\text { DS } \\
\text { DS }\end{array}$ \\
\hline
\end{tabular}

Alguns temas identificados, representam demandas/dúvidas sobre possíveis cursos a serem ofertados pela instituição, inclusive relacionados à LAI; informações sobre locais de realização de provas de vestibular; acesso ao histórico escolar e comprovante de matrícula.

\subsection{Reclamações}

Algumas das solicitações encaminhadas às IFES não diziam respeito a pedidos de informação, e sim a registros de reclamações de cidadãos.

Quadro 22. Categoria Reclamações

\begin{tabular}{|l|l|c|c|}
\hline \multicolumn{1}{|c|}{ Categoria Principal } & Temas Associados & Incidência & Classificação \\
\hline & $1^{\mathbf{o}}$ - Pedido não Atendido & 04 & DT \\
Reclamações & $2^{\text {o }}$ - Dados Desatualizados no Site & 02 & DT \\
- 12 Incidências & $3^{\text {o }}$ - Dificuldade de Inscrição em Cursos & 02 & DT \\
- 6 Temas associados & $4^{\mathbf{o}}$ - Falta de Comunicação Candidatos & 02 & DT \\
& $5^{\mathbf{o}}$ - Acesso a Diploma de Curso & 01 & DS \\
& $6^{\mathbf{o}}$ - Greve & 01 & DT \\
\hline
\end{tabular}

No Quadro 22, é apresentada a categoria "Reclamações", contendo 12 incidências e seis temas associados. Entre as demandas associadas à categoria, evidenciaram-se temas ligados a reclamações relacionadas a pedidos de acesso à informação não atendidos pelas instituições; a dados desatualizados nos sites; dificuldades de realizar inscrição em cursos ofertados pelas instituições; reclamações de candidatos que perderam prazo para realização de matrícula em cursos por falta de comunicação por parte da IFES; demora em disponibilizar diplomas de conclusão de curso, bem como assuntos relacionados às greves, caso em que o foco estava em obter informações sobre períodos de greve, motivos e cronograma de reposição das aulas.

\subsection{Finalização das Análises}

Tendo em vista que as informações manifestadas nos dados não revelavam novas descobertas, remetendo apenas aos dados já identificados, a exploração do tema foi encerrada.

\section{Conclusão}

A disponibilização de informações públicas é, seguramente, um assunto muito debatido e cobrado por toda sociedade. $\mathrm{O}$ fato de as instituições disponibilizarem informações apenas para adequar-se as exigências legais não é suficiente para sanar as demandas atuais da sociedade. Algumas vezes, a publicação exagerada de informações sem padrão e complexas acaba por ocasionar um desgaste a quem necessita de tais dados.

Dentre as contribuições desta investigação está a identificação e apresentação dos temas mais demandados pela sociedade via e-SIC em forma de categorias. Tal 
resultado colabora para que as IFES ampliem a quantidade e qualidade das informações disponibilizadas à sociedade de forma ativa em atendimento a LAI, bem como proporciona uma base referencial de informações mais solicitadas e relevantes para a sociedade.

Com a identificação dos principais temas demandados, conclui-se que a pesquisa alcançou seu objetivo e apresentou resultados importantes para auxiliar as instituições no processo de divulgação de dados, apresentando contribuição para ampliação da transparência pública com foco nas demandas da sociedade, diminuindo assim, o tempo e o esforço usualmente gasto para o atendimento dos pedidos de acesso à informação.

É preciso que as informações públicas sejam disponibilizadas para, além de promover a transparência, fomentar a inovação do país, contribuindo para a geração de renda e envolvimento da sociedade nas politicas públicas.

Contudo, para que a utilização dessas informações seja fomentada por toda a sociedade é imprescindível à disponibilização dos dados em formatos abertos. Para que o Estado, sociedade e empresas do terceiro setor possam obter bons resultados dessa proposta, é indispensável que os dados disponibilizados sejam de interesse de ambos. Neste sentido, a utilização, reutilização e aplicabilidade das informações geradas com a disponibilização de dados abertos, terá sentido se a sociedade tiver interesse em consumi-la e utilizá-la. Afinal, as instituições liberam dados com esse objetivo e as empresas privadas desenvolvem soluções buscando que a sociedade as utilize, produzindo assim um ciclo de geração, inovação e transparência com os serviços providos com esses dados.

Diante isso, este trabalho resulta em uma referência útil para gestores públicos e profissionais ligados ao processo de abertura de dados das Instituições Federais de Ensino Superior.

\subsection{Limitações da pesquisa}

Apesar de ter atingido o objetivo da pesquisa, há algumas limitações a serem consideradas. Dentre elas, esta o fato dos arquivos estatísticos coletado do e-SIC não permitir o download de categorias de instituições específicas, necessitando realizar o download de toda a base para posterior selecionar os dados desejados e, dos pedidos de acesso à informação não terem sido respondidos pela totalidade das instituições envolvidas.

\section{REFERÊNCIAS}

Bandeira, R., Cunha, C. J. C. A. (2003) Operacionalizando o método da Grounded Theory nas pesquisas em estratégia: técnicas e procedimentos de análise com apoio do software Atlas/ti. Encontro de Estudos em Estratégia, v. 1.

Brasil. (2011) Lei n. 12.527, de 18 de novembro de 2011. Regula o acesso a informações. Dispõe sobre os procedimentos a serem observados pela União, Estados, Distrito Federal e Municípios, com o fim de garantir o acesso a informações.

Cetic. (2013) Pesquisa sobre o uso das Tecnologias de Informação e Comunicação TIC Governo Eletrônico. Disponível em: <http://cetic.br/media/docs/publicacoes/2/TIC_eGOV_2013_LIVRO_ELETRONIC O.pdf $>$. 
Conte, T. and Cabral, R. and Travassos, G. (2009) Aplicando Grounded Theory na Análise Qualitativa de um Estudo de Observação em Engenharia de Software-Um Relato de Experiência. In: V Workshop "Um Olhar Sociotécnico sobre a Engenharia de Software" (WOSES 2009). p. 26-37.

Creswell, J. W. (2010). Projeto de pesquisa métodos qualitativo, quantitativo e misto. In: Projeto de pesquisa métodos qualitativo, quantitativo e misto. Artmed.

Chignard, S. (2013) A Brief Story of Open Data. Paris Tech Review. Disponível em: <http://www.paristechreview.com/2013/03/29/brief-history-open-data/>.

Diniz, V. (2010) Como conseguir dados governamentais abertos. In: Congresso Consad De Gestão Pública III. Brasília. Disponível em: $<$ https://i3gov.planejamento.gov.br/como_conseguir_dados_governamentais_abertos .pdf>.

Eaves, D. (2009) The three laws of open government data. Eaves. ca, v. 30. Disponível em: <http://eaves.ca/2009/09/30/three-law-of-open-government-data>.

Farias, F. and Cordeiro, M. (2000) Planejamento da pesquisa científica. Editora Atlas SA.

Gil, A. C. (2008) Métodos e técnicas de pesquisa social. 6. ed. São Paulo: Atlas.

Isotani, S. and Bittencourt, I. (2015) Dados Abertos Conectados. São Paulo: Novatec, $175 \mathrm{p}$.

Michener, G., Moncau, L. F. M., Velasco, R. (2014) Estado Brasileiro e Transparência: Avaliando a aplicação da Lei de Acesso à Informação. Seminário de Avaliação Nacional de Transparência Governamental, v. 1, p. 14.

Definition, O. (2015) The Open Definition; Disponível em: $<$ http://opendefinition.org/>.

OGP. (2011). OGP. Disponível em: <http://www.opengovpartnership.org/about/opengovernment-declaration>.

Pedroso, L., Tanaka, A., Cappelli, C. (2013) A Lei de Acesso à Informação brasileira e os desafios tecnológicos dos dados abertos governamentais. IX Simpósio Brasileiro de Sistemas de Informação.

Strauss, A. and Corbin, J. (2008) Basics of Qualitative Research: Techniques and Procedures for Developing Grounded Theory. Thounsand Oaks: Sage Publications.

Strauss, A. and Corbin, J. (1998) Pesquisa qualitativa: técnicas e procedimentos para o desenvolvimento de teoria fundamentada. Artmed. 